\title{
Evaluation of bioactivity and phytochemical screening of endophytic fungi isolated from Ceriops decandra (Griff.) W. Theob, a mangrove plant in Bangladesh
}

Mita Munshi', Md. Hossain Sohrab², Mst. Nadira Begum³ ${ }^{3}$ Sattyajit Roy Rony², Md. Adnan Karim,4, Farhana Afroz ${ }^{2^{*}}$ and Md. Nazmul Hasan ${ }^{1,5^{*}}$

\begin{abstract}
Background: Due to increasing number of individuals within the world having health issues caused by varied cancers, drug-resistant microorganism, parasitic protozoans, and fungi could be a cause for alarm. Endophyte's are a unique source of medicinal compounds which requires an intensive seek for newer and simpler agents to handle these sickness issues is currently advancing. This study explores the description of endophytic fungi of Ceriops decandra (Griff.) W. Theob., a mangrove plant growing in mangrove forest, Sundarban, Bangladesh.

Methods: The endophytic fungi of experimental plants were identified by DNA amplification and sequencing of the internal transcribed spacer (ITS) region Moreover, cytotoxicity, antioxidant and antimicrobial tests were assessed. In addition, the screening of extracts was performed by visual detection using UV light.

Results: Three fungi namely CEDBE-1, CEDLE-6 and CEDLE-10 (internal strain no) were isolated as endophytic fungi and identified as Fusarium oxysporum, Clonostachys spp. and Fusarium solani respectively on the basis of morphological characteristics and DNA sequencing. The isolates were cultured at $28^{\circ} \mathrm{C} \pm 2$ for 21 days in Potato Dextrose Agar (PDA) media. The extracts of fungal isolates were examined at $100 \mu \mathrm{g} /$ disc concentration for the screening of antibacterial activity and exhibited no activity against tested human pathogenic bacteria. The strain CEDBE-1 showed highest antioxidant activity of $\mathrm{IC}_{50}$ value of $31.07 \mu \mathrm{g} / \mathrm{mL}$ comparing with the positive control ascorbic acid (0.74) and BHA (7.79) $\mu \mathrm{g} / \mathrm{mL}$. All isolates exhibited strong cytotoxic activity using brine shrimp lethality bioassay compared with the positive control tamoxifen. Preliminary chemical screening of the fungal extracts by thin layer chromatography technique revealed the presence of various compounds.

Conclusions: The findings indicate that endophytic fungal isolates explored from C. decandra has diversified biological activities which may be potential source of leads for new drug development.
\end{abstract}

Keywords: Ceriops decandra (Griff.) W. Theob, endophytic fungi, molecular identification, phylogenetic analysis

\footnotetext{
* Correspondence: farhana04@yahoo.com; mnhasan1978@gmail.com;

mn.hasan@just.edu.bd

${ }^{2}$ Pharmaceutical Sciences and Research Division, Bangladesh Council of

Scientific and Industrial Research, 1205 Dhaka, Bangladesh

'Laboratory of Pharmaceutical Biotechnology and Bioinformatics,

Department of Genetic Engineering and Biotechnology, Faculty of Biological

science and Technology, Jashore University of Science and Technology, 7408

Jashore, Bangladesh

Full list of author information is available at the end of the article
}

\section{Springer Open}

(c) The Author(s). 2021 Open Access This article is licensed under a Creative Commons Attribution 4.0 International License, which permits use, sharing, adaptation, distribution and reproduction in any medium or format, as long as you give appropriate credit to the original author(s) and the source, provide a link to the Creative Commons licence, and indicate if changes were made. The images or other third party material in this article are included in the article's Creative Commons licence, unless indicated otherwise in a credit line to the material. If material is not included in the article's Creative Commons licence and your intended use is not permitted by statutory regulation or exceeds the permitted use, you will need to obtain permission directly from the copyright holder. To view a copy of this licence, visit http://creativecommons.org/licenses/by/4.0/. 


\section{Introduction}

Sundarban is a leading single source of mangrove forest in the world [1]. More than a number of its plant species have massive applications within the convention of folk medicine; numerous components of those plants are applied for the native folks as cure for numerous ailments [2-4]. Yet such colossal potential, few reports are available on these species relating to their biological activities and therefore, the active principles liable to such activities. An endeavor has been created during this analysis to extend the notice for the therapeutic significance as conservation and utilization of those mangrove species as natural affluent sources of novel bioactive agents. As mangroves thrive in enormously traumatic and unfriendly environment of high salinity, high and low tides of water, heat and humidity, sturdy winds and muddy anaerobic soil that the group of plants ought to have extremely developed morphological and physiological variations to such extreme conditions. These exceptional characteristics may result in the synthesis of novel chemical compounds; these chemical compounds recommend protection to those plants against numerous biotic and abiotic stresses [5]. Endophytic microflora resides in the host plants while not inflicting any ailment symptoms. Solely a number of plants are studied for their endophyte variety and their potential to provoke bioactive secondary metabolites [6]. Approximately, all the plants are well- known to harbor for endophytes. The selection of the plant may be the resource of secondary metabolites [7]. Exploration of endophytes and their bioactivities is very important because the endophytic fungi have a very important relationship in some co-existing endophytes and their host plants, which might considerably influence the formation of metabolites in plants, then have an effect on quality and extent of crude medicine derived from healing plants over the long era of evolution [8].

C. decandra is a mangrove plant of tropical Asia belonging to the family Rhizophoraceae. It is grown as a shrub or small tree up to $15 \mathrm{~m}(50 \mathrm{ft})$ tall with a trunk diameter of up to $30 \mathrm{~cm}$ (12 in) found naturally in India and Bangladesh (including the Sundarbans), Burma, Thailand and Peninsular Malaysia [9]. This plant has strong antioxidant activity.

Furthermore, this plant has reputation for its folkloric uses in the treatment of gastrointestinal disorders, infection, snakebites, inflammation, and cancer. Various phytoconstituents which include diterpenoids (ceriopsin A-G), triterpenoids (lupeol, $\alpha$-amyrin, oleanolic acid, ursolic acid), and phenolics (catechin, procyanidins) are present in different parts of the plant. These phytoconstituents and their derivatives could form a new basis for developing new drugs against various diseases [10].
Profuse use of profitable antibiotic and manufactured pesticides for human and crop protection is detrimental to human health, ecology and atmosphere. Attention has additionally been drawn to the antimicrobial properties of plants and their metabolites owing to the growing incidences of drug-resistant pathogens of each clinical and agricultural importance [11]. Thus, this research was carried out to study the bioactivity of endophytic fungi associated with $C$. decandra so that it could be a potential source leading to the development of new drug.

\section{Materials and methods}

\section{Isolation of fungal material}

The plant samples were accumulated from conservation forest of Sundarban, Bangladesh in February, 2018. The plant material was recognized and authenticated by a taxonomist of Bangladesh National Herbarium (BNH), Dhaka, Bangladesh. A voucher specimen of this compilation was retained at $\mathrm{BNH}$ under the accession number DACB - 45,945. Fungal strains were isolated from the fresh plant parts following the procedure described by Khan et al. 2018 [12, 13].

\section{Taxonomical identification of fungal cultures Morphological identification}

Slides were prepared from cultures by staining with lactophenol cotton blue examined with a bright-field and phase contrast microscope for the identification of endophytic fungal strains (Sadananda, Govindappa et al., 2014). Likewise, the standard taxonomic keys such as growth pattern, hyphae, the color of the colony and medium, margin character, aerial mycelium, surface, texture, sporulation and production of acervuli, the size and coloration of the conidia were used to identify morphological characteristics $[14,15]$.

\section{Molecular identification}

Fungal strains were identified by DNA amplification and sequencing of the internal transcribed spacer (ITS) region [16]. A section of fungal hyphae $\left(0.5-1.0 \mathrm{~cm}^{2}\right)$ was assembled from the Petridish and lyophilized in an Eppendorf tube ( $2 \mathrm{~mL}$, Eppendorf, Germany). With the help of glass beads the lyophilized fungal mycelia were pulverized and agitated. In keeping with the manufacturer's protocol, fungal DNA isolation was acquired by using DNeasy Plant Mini Kit (QIAgen, USA). Cell lysis, digestion of RNA by RNase A, removal of precipitates and cell debris, DNA shearing; precipitation and purification were assimilated in the method. The isolated DNA was then amplified by polymerase chain reaction (PCR). The PCR was conceded utilizing HotStarTaq Master Mix Kit (QIAgen, USA). ITS 4 (with base sequences TCCGTAGGTGAACCTGCGG) and ITS 5(with base sequences TCCTCCGCTTATTGATATGC) 
(Invitrogen, USA), as primers, were mixed with HotStarTaq Master Mix Kit and DNA template in a total volume of $50 \mu \mathrm{L}$. The mixture was then applied to the thermal cycler (BioRad, USA) using the programmed PCR cycle as outlined below: Initial activation step in $95{ }^{\circ} \mathrm{C}$ for 15 min to activate HotStarTaq DNA polymerase, cycling steps which were restated 35 times, denaturing: $1 \mathrm{~min}$ at $95{ }^{\circ} \mathrm{C}$, annealing: $1 \mathrm{~min}$ at $56{ }^{\circ} \mathrm{C}$, extension: $1 \mathrm{~min}$ at $72{ }^{\circ} \mathrm{C}$, final extension for $10 \mathrm{~min}$ in $72{ }^{\circ} \mathrm{C}$. The PCR product was purified using $2 \%$ Agarose-GelElectrophoresis at $75 \mathrm{~V}$ for $60 \mathrm{~min}$ in $1 \mathrm{X}$ TBE buffer. The agarose gel was then stained using $1 \%$ ethidium bromide. An approximate size 550 bp stained DNA fragment was then wiped out from the agarose gel. By following manufacturer's protocol, PCR product purification was carried out using Perfect Prep Gel Cleanup Kit (Eppendorf, USA). The amplified fungal DNA (PCR product) was then submitted for sequencing by a viable service and the base sequence was evaluated with publicly accessible databases such as GenBank with the help of Blast-Algorithms.

\section{Bioactivity screenin \\ Brine shrimp lethality bioassay}

According to Meyer et al. Brine shrimp lethality bioassay was implemented to inspect the cytotoxicity of the extract [17]. Serial dilution was then carried out in order to obtain the concentration of $1.25 \mu \mathrm{g} / \mathrm{mL}$ to $320 \mu \mathrm{g} /$ mL. $5 \mathrm{~mL}$ of artificial sea water was added into all the test tubes. Artificial seawater (prepared by using sea salt $38 \mathrm{~g} / \mathrm{L}$ and adjusted to $\mathrm{pH} 8.5$ using $1 \mathrm{~N} \mathrm{NaOH}$ ) was used to hatch the eggs of the brine shrimps (Artemia salina) under constant aeration for $24 \mathrm{~h}$ under the light. To get shrimp larvae, the hatched shrimps were permitted to grow by $48 \mathrm{~h}$. Suspension containing 10 nauplii was added into each test tube and was incubated at room temperature under the light. The tubes were then examined after $24 \mathrm{~h}$ and the number of surviving larvae in each test tube was counted with the aid of a magnifying glass. The percentage of mortality was plotted against the logarithm of concentration. The concentration that would kill $50 \%$ of the nauplii $\left(\mathrm{LC}_{50}\right)$ was determined from probit analysis as well as linear regression equation using the software "Microsoft Excel-2007". Tamoxifen was used as standard in this bioassay [18].

\section{Antimicrobial screening}

The antimicrobial and antifungal activities were investigated by the procedure explained by Bauer et al. [19]. The test microorganisms used in the antimicrobial study incorporated four pathogenic bacterial strains Staphylococcus aureus (ATCC 25,923), Escherichia coli (ATCC 28,739), Bacillus megaterium (ATCC 259), Salmonella typhi (ATCC 28) and one fungal strains Aspergillus niger. After $18-24 \mathrm{~h}$ of incubation at $37{ }^{\circ} \mathrm{C}$ for bacteria and $48-96 \mathrm{~h}$ of incubation at $28{ }^{\circ} \mathrm{C}$ for fungi, the zones of growth inhibition around the discs were measured. By determining the diameter of inhibitory zones in millimeter compared to kanamycin $(30 \mu \mathrm{g} /$ disc $)$ as a positive control and ketoconazole (30 $\mu \mathrm{g} /$ disc) as standard antibiotics for antibacterial and antifungal screening, correspondingly the sensitivities of the microorganism species to the fungal extract were calculated.

\section{Initial screening by Thin Layer Chromatography (TLC)}

This screening of the extract was performed by visual detection, UV light (in short and long wavelength) and vanillin- $\mathrm{H}_{2} \mathrm{SO}_{4}$ spray reagent.

\section{Chemical screening}

For identification of chemical constituents of endophytic fungal crude extracts the extracts were subjected to thin layer chromatographic technique. Commercially available precoated silica gel (Kiesele gel 60 PF 254) plates were used with solvent system of toluene: $10 \%$ ethyl acetate for the initial chemical screening of the crude extracts.

\section{Statistical analysis}

$\mathrm{IC}_{50}$ values between groups were compared using independent student's t-tests. For the analysis of the cytotoxicity results for each extract, continuous variables between groups were compared with one-way analysis of variance (ANOVA) with post hoc Tukey's test. Mean values between groups were compared using independent student $t$-test for equality of variances. Statistical significance was accepted when $P<0.001$.

\section{Results}

Isolation and morphological grouping of endophytic fungi from $\mathrm{C}$. decandra

In this investigation, a total 30 segments (14 leaves and 16 barks) of $C$. decandra were inoculated in the plate and a total 25 isolates were purified on the basis of morphological characteristics using standard protocol [15]. These fungal isolates were successfully identified up to genus level as two species Fusarium and one species Clonostachys. They exhibited characteristic colony and microscopic morphology that could be used to differentiate them. The colonies of Fusarium appeared yellowish or dull white in color (Fig. 1A \& B). In microscopy, Fusarium spores exhibited 1-celled, cylindrical, 6-15 $\times 3$ $4 \mu \mathrm{m}$ in size, conidia was elliptical to cylindrical, with 0 to 2 septa curved (Fig. 1C). Acervuli was in groups, sometimes appeared like circular bodies emerging from yellowish white spots. Conidial mass was yellow in the middle and the rest portion was white. Mycelium was also yellowish white (Fig. 2). Strain no CEDLE-6 was 

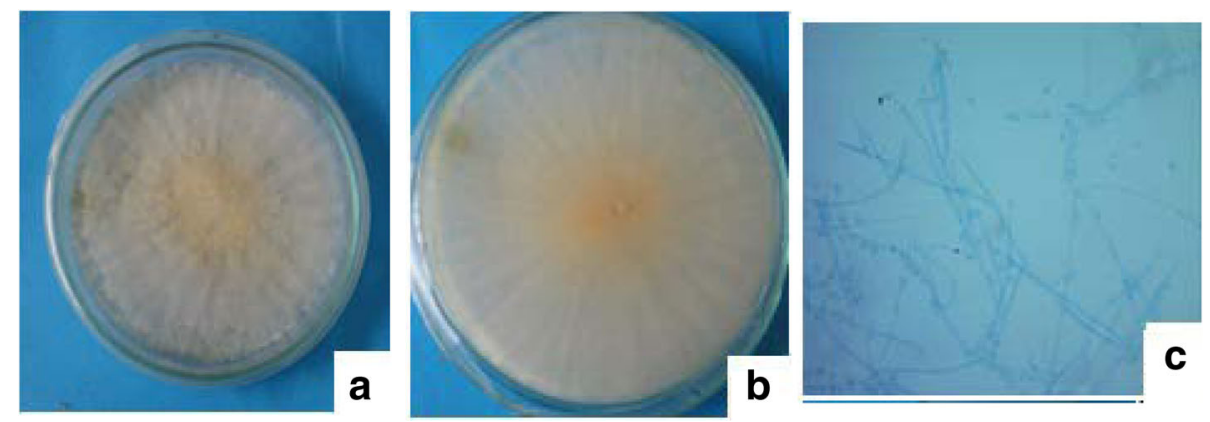

Fig. 1 Macroscopic front (A) macroscopic (B) and microscopic (C) view of Fusarium sp. The pictures (A, B) represent macroscopic view of Fusarium sp. from leaf of $\mathbf{C}$. decandra after 12 days of cultivation on PDA media and also represent microscopic view (40X) (C)

presumed the new strain of Clonostachys sp. as the BLAST results showed $91.58 \%$ similarity between Clonostachys sp. and Clonostachys rosea. Some of the differences were observed between Clonostachys sp. and $C$. rosea. Colonies of Clonostachys sp. were irregularly cottony and usually gray to black where the dark brown mature conidia eventually formed, whereas the colonies of $C$. rosea was grayish green to olivaceous green and the conidial mass was also grayish to olivaceous green (Fig. 3). Moreover, Conidia were 3-5 ×5-10 $\mu \mathrm{m}$ in size, rough; fairly thin walled, oblong and usually two cells in studied Clonostachys sp. in as much as conidiophores of C. rosea were $25-200 \times 3.5-5.5 \mu \mathrm{m}$ in size. Furthermore, the conidiophores of C. rosea were verticillium-like, while the conidia of Clonostachys sp. were spindle-like [18]. In addition, hyphae were septate, phialides were erect, unbranched, tapering and form directly on the fine, narrow hyphae in case of Clonostachys sp.

\section{Molecular identification and phylogenetic analysis of isolates}

Molecular characterization of fungal endophytes provides evidence about the separation of morphologically identical fungi which may vary enough genetically to be considered separate species, and in some cases to be placed into different clades. Based on BLAST analysis, the sequence likeness considered 95-100\%. Three species were identified as representing two genera which is shown in Table 1.

The generic name of fungal strain CEDBE- 1 was analyzed on the basis of 5.8 S-rRNA-ITS regions and examined the phylogenetic relationship with the published data. As seen in Fig. 4 fungal isolates CEDBE-1exhibited $100 \%$ similarity to other fungal isolates $F$. oxysporum (accession no. MK828120.1) that itself was identified as F. oxysporum, similarly to other species (100\%, accession numbers LT841236.1, LT841222.1 etc.) deposited in the U.S. National Center for Biotechnology Information (NCBI). Finally, CEDBE-1 was identified as $F$. oxysporum by comparing with the morphological key features.

Next fungal strain CEDLE-6 was presumed to be Chlonostachys sp. based on the phylogenetic relationship for 5.8SRNA-ITS regions as shown in Fig. 5 and comparison of the 5.8SRNA-ITS regions with available sequences in the database, namely the base sequences which showed $98 \%$ similarities with Hypomyces corticolia (accession no MH860037.1) and 91.58\% similarities with C. rosea (accession no MH862790.1). On the basis of morphological characteristics finally it was concluded that strain CEDLE-6 Chlonostachys sp. registered as KY320599.1.

Based on the analysis of 5.8 S-rRNA-ITS regions of CEDLE-10 this fungal strain showed $100 \%$ similarity with the genus F. solani (accession no. KC577186.1)
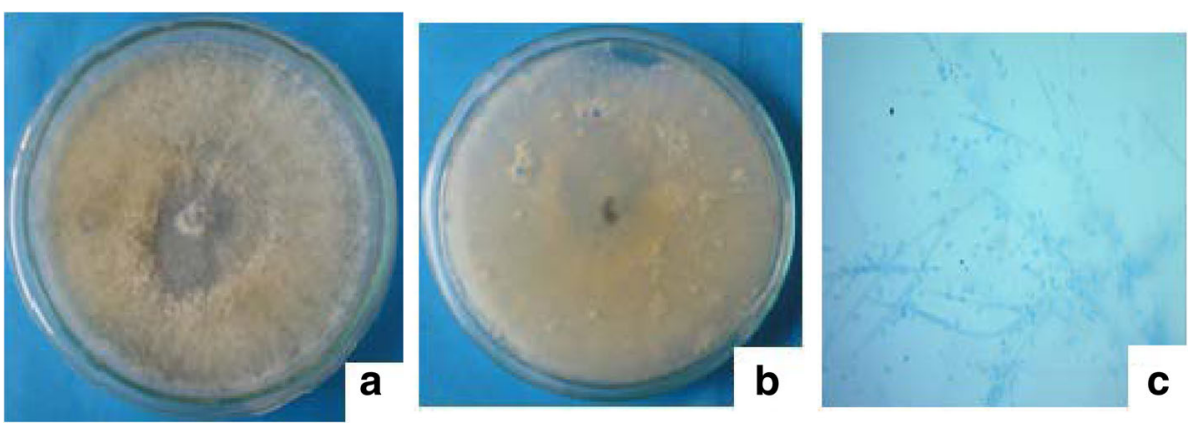

Fig. 2 Macroscopic front (A) macroscopic (B) and microscopic (C) view of Fusarium sp. The pictures (A, B) represent macroscopic view of Fusarium sp. from bark of $C$. decandra after 12 days of cultivation on PDA media and also represent microscopic view (40X) (C) 

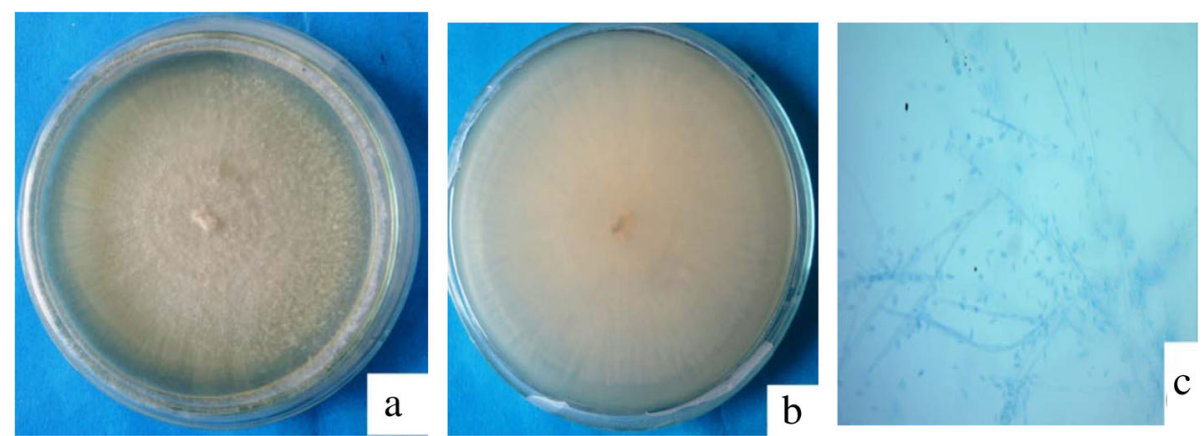

Fig. 3 Macroscopic front (A) macroscopic (B) and microscopic (C) view of Clonostachys sp. The pictures (A, B) represent macroscopic view of Clonostachys sp. from leaf of C. decandra after 12days of cultivation on PDA media and also represent microscopic view (40X) (C)

where other texa F.solani (accession no. AB190389.1) showed very close phylogenetic relationship with the $F$. solani which is shown in Fig. 6. By comparison with the available sequences in the database and morphological keynotes it has been clarified CEDLE-10 as F. solani.

\section{Bio-screening of isolated fungal isolates Cytotoxicity test}

Extracts of the plant $C$. decandra and its associated endophytic fungal strains CEDBE-1, CEDLE-6 and CEDLE-10 were screened for probable cytotoxic activities using brine shrimp lethality bioassay and the result is represented as a bar graph in Fig. 7 . The $\mathrm{LC}_{50}$ value of crude methanol extract of the plant was found to be $8.67 \mu \mathrm{g} / \mathrm{mL}$. On the other hand, extracts of the fungal strains CEDBE-1, CEDLE- 6 and CEDLE10 were found to be $0.87 \mu \mathrm{g} / \mathrm{mL}, 1.03 \mu \mathrm{g} / \mathrm{mL}$ and $2.68 \mu \mathrm{g} / \mathrm{mL}$ respectively. It is noticed that all the test samples were lethal to brine shrimp nauplii. By contrasting these values with tamoxifen as positive control, it was noticed that crude fungal extracts had remarkable cytotoxicity to brine shrimp.

\section{Antioxidant test}

The free radical scavenging activity (Fig. 8) of different extracts from $C$. decandra and its associated endophytic fungal strains were assayed by using DPPH scavenging method (Dame et al., 2016). In this assay, fungal strain CEDBE-1 showed highest antioxidant activity with $\mathrm{IC}_{50}$ value of $31.07 \mu \mathrm{g} / \mathrm{mL}$ compared with $\mathrm{IC}_{50}$ values of positive control $0.74,7.79$ for ascorbic acid and BHA respectively whereas CEDLE-6 and CEDLE-10 exhibited moderate antioxidant activity with $\mathrm{IC}_{50}$ values of 88.22 and $141.86 \mu \mathrm{g} / \mathrm{mL}$, respectively. These results indicate that CEDBE-1 has immense antioxidant capacity which may have potentiality to release antioxidant metabolites.

\section{Antimicrobial test}

All isolates were screened for antimicrobial activity adjacent to a wide variety of human pathogenic bacteria and fungi. The results of the antimicrobial tests of ethyl acetate extracts of laboratory culture of three endophytic fungi are listed in Table 2. Isolate CEDLE-10 exhibited potential antimicrobial activity against all tested human pathogenic bacteria except $S$. aureus. Other isolates CEDBE-1 and CEDLE-6 showed moderate activity against only $S$. typhi.

\section{Chemical screening}

All the extracts qualitatively tested for presence of chemical constituents. The screening of extracts was performed by visual detection, UV light (both in short at $254 \mathrm{~nm}$ and in long at $365 \mathrm{~nm}$ ) and all of these results are presented in Table 3. Thin layer chromatographic technique was used in solvent system (Toluene: Ethyl acetate $=90 \%: 10 \%$ ) to identify the presence of different secondary metabolites. This result indicates the presence of a good number of compounds like flavonoids, terpenoids, carotenoids, anthocyanins etc.

Table 1 Molecular identification using ITS regions of endophytic fungi isolated from Ceriops decandra plant

\begin{tabular}{llllcll}
\hline Fungal Species & Max & $\begin{array}{l}\text { Total } \\
\text { Score }\end{array}$ & $\begin{array}{l}\text { Query } \\
\text { Cover }\end{array}$ & E-Value & $\begin{array}{l}\text { \% } \\
\text { Similarity }\end{array}$ & Accession No. \\
\hline Fusarium oxysporum & 1055 & 1055 & $100 \%$ & 0 & $100.00 \%$ & MK828120.1 \\
Clonostachys sp. & 760 & 760 & $98 \%$ & 0.0 & $91.58 \%$ & KY320599.1 \\
Fusarium solani & 1020 & 1020 & $99 \%$ & 0.0 & $100.00 \%$ & KC577186.1 \\
\hline
\end{tabular}




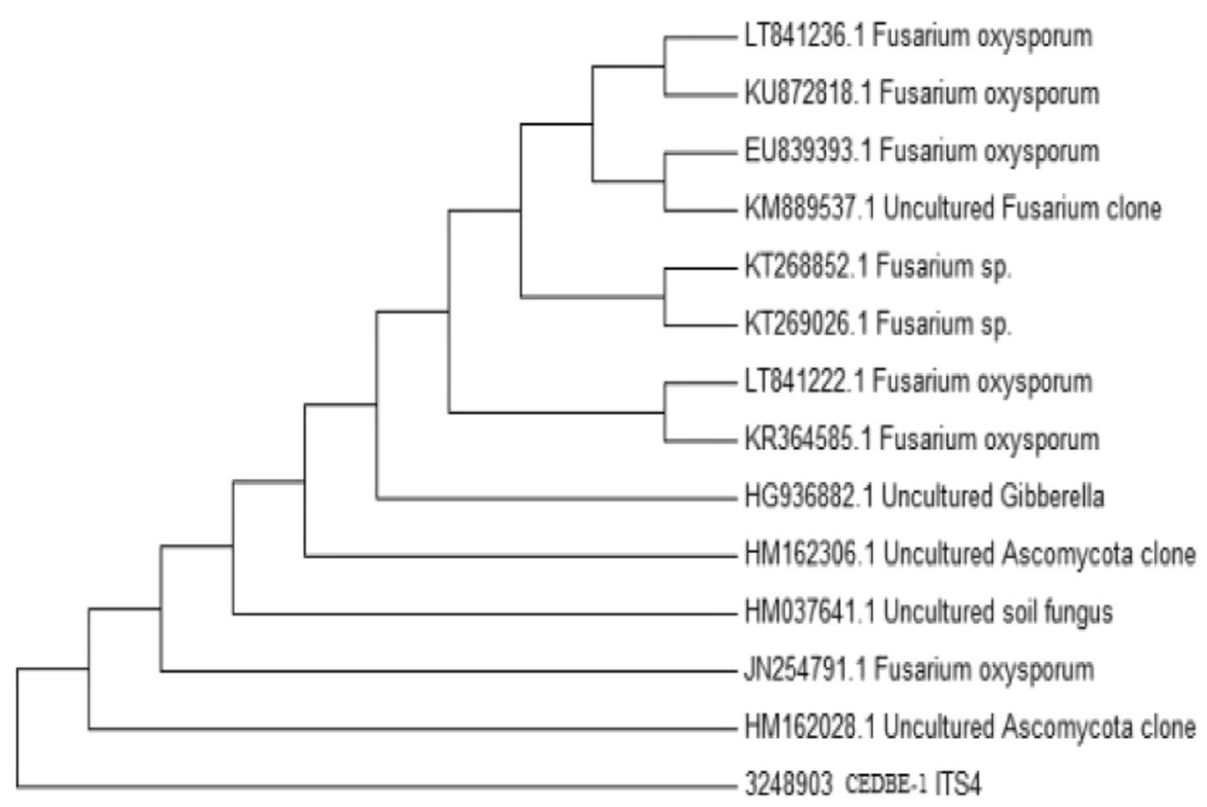

Fig. 4 Phylogenetic relationship for 5.8S-rRNA-ITS regions between the endophytic fungus CEDBE-1 and published data. Phylogenetic tree constructed using Neighbor-Joining (NJ) method with bootstrap support based on 1,000 replicates, and evolutionary distances computed using the Maximum Composite Likelihood method based on 5.8S-rRNA-ITS sequences

\section{Discussion}

Plants have been known as latent sources for novel drug compounds and many plant extracts have been used as substitute of medical treatments since the late 1990s Mangroves are pervasive in tropical and subtropical regions, especially in Asia, and they are unique for their saline environment which promises innovation of biologically active compounds, for instance antiviral, antibacterial and antifungal. $C$. decandra, a mangrove plant species, has been known to be a source of many bioactive compounds which could be found within the bark and leaves of the plants. The present study shows that the bioactive

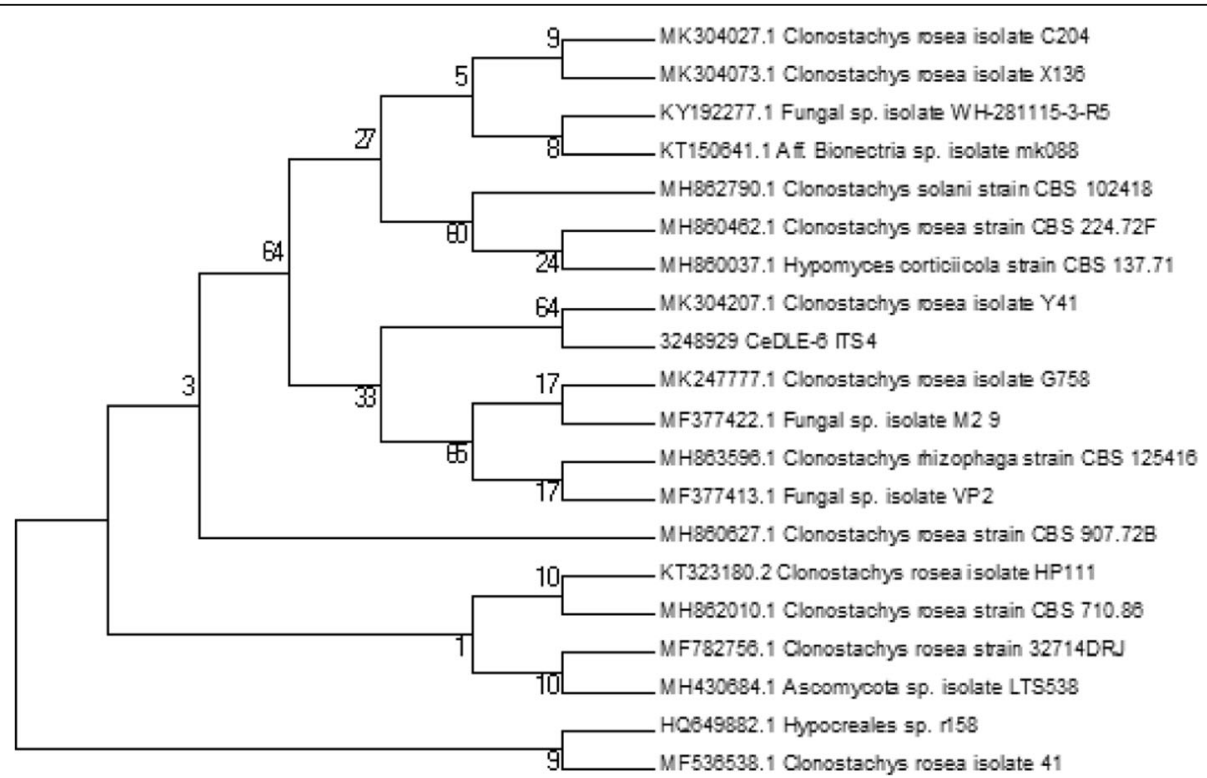

Fig. 5 Phylogenetic relationship for 5.8S-rRNA-ITS regions between the endophytic fungus CEDLE- 6 and published data. Phylogenetic tree constructed using Neighbor-Joining (NJ) method with bootstrap support based on 1,000 replicates, and evolutionary distances computed using the Maximum Composite Likelihood method based on 5.8S-rRNA-ITS sequences 


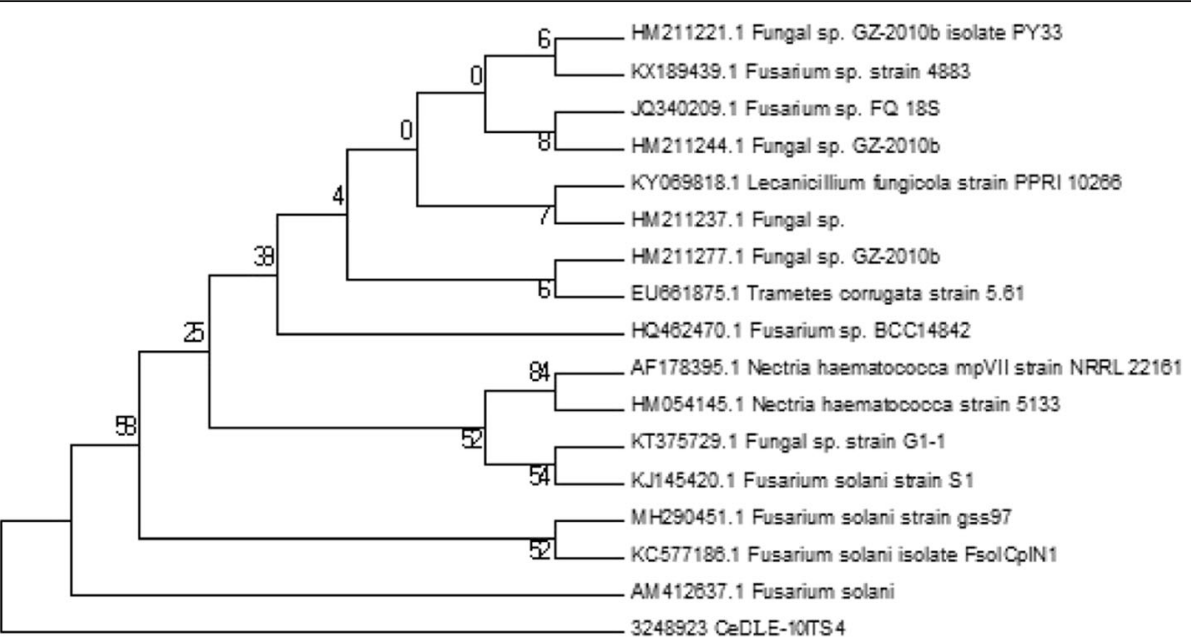

Fig. 6 Phylogenetic relationship for 5.8S-rRNA-ITS regions between the endophytic fungus CEDLE-10 and published data. Phylogenetic tree constructed using Neighbor-Joining (NJ) method with bootstrap support based on 1,000 replicates, and evolutionary distances computed using the Maximum Composite Likelihood method based on 5.8S-rRNA-ITS sequences

properties of $C$. decandra collected from the mangroves in Sundarban, might be due to the activity of fungal endophytes found within the leaves and barks of the mangrove plant.

This is the first report on the isolation of endophytic fungi isolated from $C$. decandra (mangrove plant). In October 2010, endophytic bacteria from leaves of mangrove and salt-marsh plant species were isolated by Gayathri, Saravanan et al. in India and they proved that the mangroves were the sources of endophytic bacteria with bioprospecting potential. [20].
Extracts of the plant $C$. decandra and its associated endophytic fungal strains CEDBE-1, CEDLE- 6 and CEDLE-10 were screened for probable cytotoxic activities using brine shrimp lethality bioassay. The LC50 value of crude methanol extract of the plant was found to be $8.67 \mu \mathrm{g} / \mathrm{mL}$. On the other hand, extracts of the fungal strains CEDBE-1, CEDLE- 6 and CEDLE-10 were found to be $0.87 \mu \mathrm{g} / \mathrm{mL}, 1.03 \mu \mathrm{g} / \mathrm{mL}$ and $2.68 \mu \mathrm{g} / \mathrm{mL}$ respectively. It is apparent that all the test samples were lethal to brine shrimp nauplii. By evaluating these values with tamoxifen as positive control, it was found that

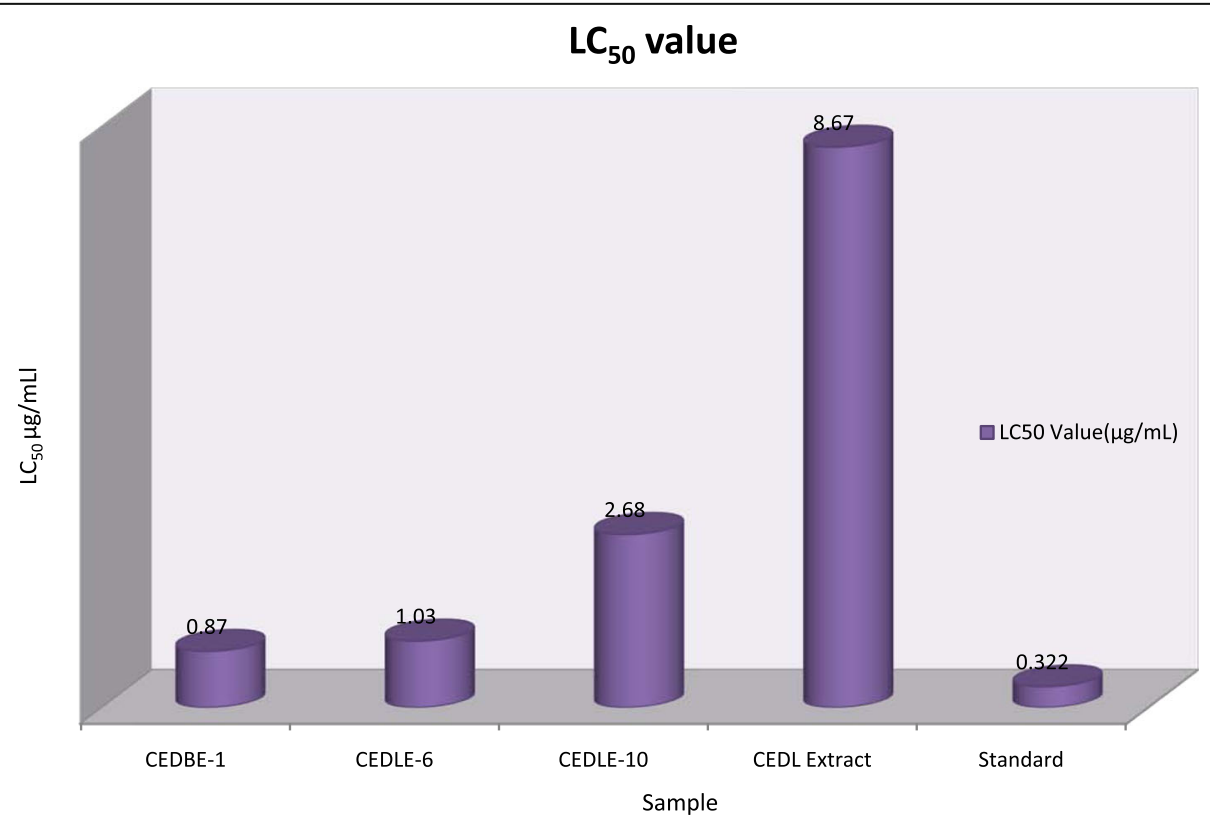

Fig. 7 Cytotoxic effect of crude extracts on brine shrimp nauplii 


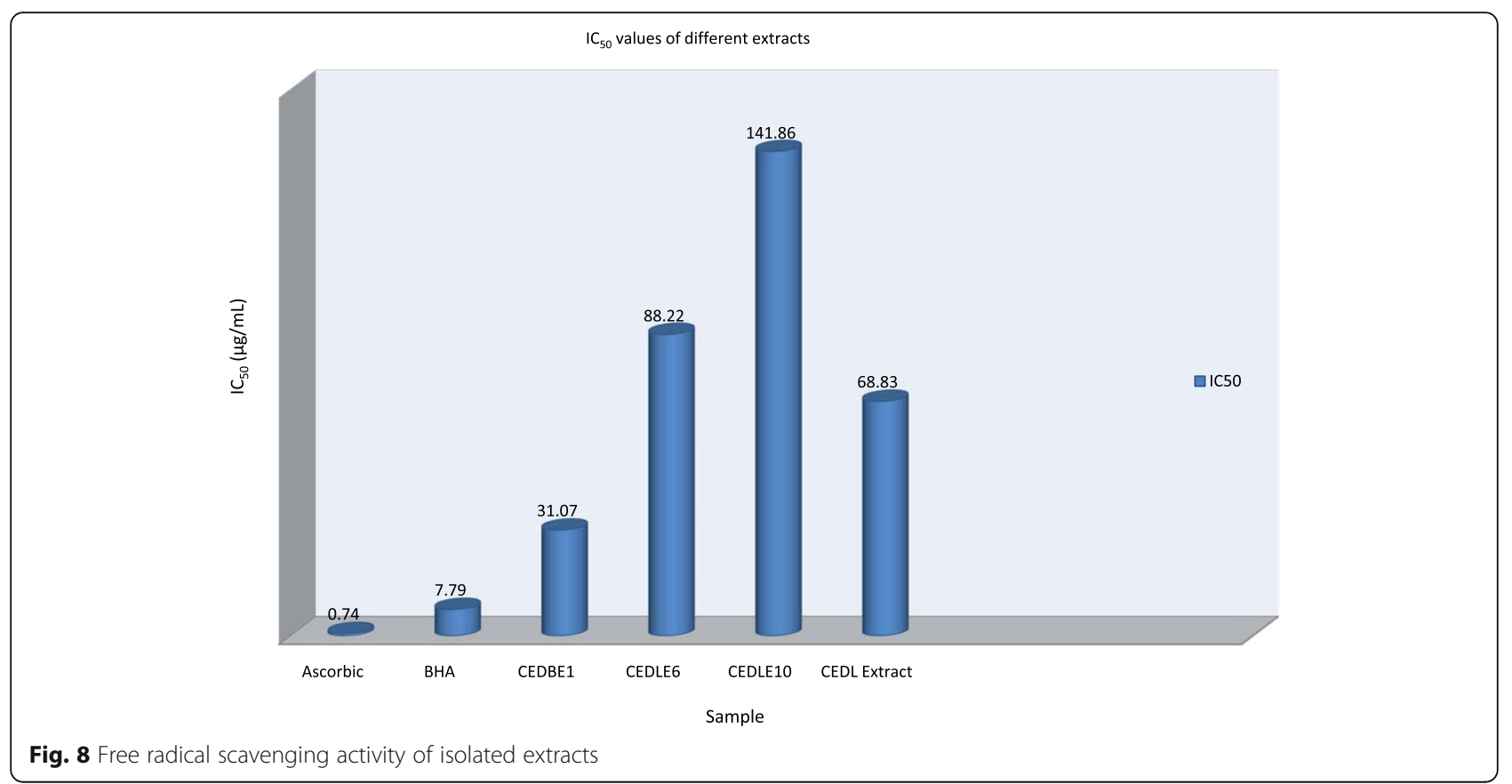

crude fungal extracts illustrated effective cytotoxicity to brine shrimp. Bhimba et al. (2011) characterized the cytotoxic compound from mangrove-derived fungi Irpex hydnoides VB4. The fungal extract (tetradecan) isolated from the endophytic fungi showed very potent cytotoxic effect, indicating its possible potential for development as an anticancer drug, and warrants further scientific investigation [21].

The fungal strain CEDBE-1 showed highest antioxidant activity with $\mathrm{IC}_{50}$ value of $31.07 \mu \mathrm{g} / \mathrm{mL}$ compared with $\mathrm{IC}_{50}$ values of positive control $0.74,7.79$ for ascorbic acid and BHA respectively. CEDLE- 6 and CEDLE-10 exhibited moderate antioxidant activity with $\mathrm{IC}_{50}$ values of 88.22 and $141.86 \mu \mathrm{g} / \mathrm{mL}$, respectively. These results designate that CEDBE-1 has elevated antioxidant capacity which may have potentiality to be a treatment for averting certain diseases, being either the cause or the consequence of reactive oxygen species. Huang and coworkers (2007) suggested that the phenolic contents were the major antioxidant constituents of the endophytes [22]. Moreover, Bharathidasan et al. found Phomopsis amygdali, an endophytic fungus isolated from the mangrove plant in Karankadu, India, showed potent antioxidant activity against both ABTS and DPPH radicals [23].

Isolate CEDLE-10 exhibited potential antimicrobial activity against all tested human pathogenic bacteria except $S$. aureus. Other isolates CEDBE- 1 and CEDLE-6 showed moderate activity against only $S$. typhi. None of the endophytes exhibited any activity next to the tested pathogenic fungi. Some other researchers' also isolated 71 endophytic fungi with antimicrobial potentiality from mangrove plants towards elected bacteria (Bacillus subtilis, Pseudomonas aeruginosa, E. coli and S. aureus) was hardened using ethyl acetate extracts of fungi cultured under stagnant circumstances. All test bacteria were

Table 2 Antimicrobial Screening of Isolated Compounds

\begin{tabular}{|c|c|c|c|c|c|c|}
\hline \multirow{4}{*}{$\begin{array}{l}\text { Sample } \\
(100 \mu \mathrm{g} / \mathrm{disc})\end{array}$} & \multicolumn{6}{|c|}{ Diameter of Zone of Inhibition (mm) } \\
\hline & \multicolumn{5}{|l|}{ Bacterial Strain } & \multirow{3}{*}{$\begin{array}{l}\text { Fungal Strain } \\
\text { A. niger }\end{array}$} \\
\hline & \multicolumn{3}{|l|}{ Gram positive } & \multicolumn{2}{|c|}{ Gram negative } & \\
\hline & B. megaterium & & S. aureus & S. typhi & E. coli & \\
\hline CEDBE-1 & --- & & --- & 7 & --- & --- \\
\hline CEDLE-6 & --- & & --- & 8 & --- & --- \\
\hline CEDLE-10 & 9 & & --- & 7 & 7 & --- \\
\hline Positive control & KM & 40 & 36 & 47 & 48 & --- \\
\hline (30 $\mu \mathrm{g} / \mathrm{disc})$ & KC & & --- & --- & --- & --- \\
\hline
\end{tabular}

KM - Kanamycin; KC - Ketoconazole; "-" indicates no sensitivity; nd: indicates not done 
Table 3 Chemical screening of crude extracts of C. decandra and its associated fungi

\begin{tabular}{|c|c|c|c|c|}
\hline Strain no & Visual & $254 \mathrm{~nm}$ & $365 \mathrm{~nm}$ & $\begin{array}{l}\text { Remarks on probable } \\
\text { compounds }\end{array}$ \\
\hline CED & $\begin{array}{l}\text { Yellow, Brown, } \\
\text { Yellow }\end{array}$ & No color & Red, Orange, & $\begin{array}{l}\text { Flavonoids, } \\
\text { Terpenoids, } \\
\text { Carotenoid }\end{array}$ \\
\hline $\begin{array}{l}\text { CEDBE-1 } \\
\text { (Organic Part) }\end{array}$ & $\begin{array}{l}\text { Purple, } \\
\text { Pink }\end{array}$ & $\begin{array}{l}\text { Dark quenching spot, Light purple, } \\
\text { Light purple }\end{array}$ & $\begin{array}{l}\text { Spot purple, Dark quenching } \\
\text { purple. }\end{array}$ & Anthocyanin \\
\hline $\begin{array}{l}\text { CEDBE-1 (Aqueous } \\
\text { part) }\end{array}$ & Purple & No color & $\begin{array}{l}\text { Spot purple, } \\
\text { Dark quenching purple. }\end{array}$ & Anthocyanin \\
\hline $\begin{array}{l}\text { CEDLE-6 } \\
\text { (Organic part) }\end{array}$ & Yellow & Dark quenching purple, Light purple & $\begin{array}{l}\text { Spot purple, Dark quenching } \\
\text { spot, Purple }\end{array}$ & Anthocyanin \\
\hline $\begin{array}{l}\text { CEDLE-10 } \\
\text { (Organic part) }\end{array}$ & Purple, Pink & $\begin{array}{l}\text { Dark quenching purple, Orange, Light } \\
\text { purple. }\end{array}$ & Dark quenching spot & Anthocyanin \\
\hline $\begin{array}{l}\text { CEDLE-10 } \\
\text { (Aqueous part) }\end{array}$ & Pink & Purple, Light brown, Brown & Purple & Anthocyanin \\
\hline
\end{tabular}

repressed by a Cladosporium sp. isolated from the leaves of T. populneoides and an endophytic Xylaria sp. 1 isolated from $A$. ilicifolius leaves caused significant inhibition to Gram-positive and Gram-negative bacteria [24].

\section{Conclusions}

This study supports the growing indication that bioactive substances are generated by fungal endophytes $F$. oxysporum, Clonostachys sp. and F. solani. In a continuation of seeking bioactive secondary metabolites from natural sources at our laboratory, chemical exploration of ethyl acetate extract of Clonostachys sp. and F. solani strain isolated from $C$. decandra led to the isolation of effective secondary metabolites. Results of this investigation showed that CEDBE-1, CEDLE-6, CEDLE-10 and crude extract have potentiality as bioactive compounds against cytotoxicity, anti-microbial and antioxidant test. Thus, evidences indicated that F. oxysporum, Clonostachys sp. and F. solani strain are good sources of bioactive compounds.

\section{Acknowledgements}

The authors are thankful to the authority of BCSIR for providing laboratory facilities and also thankful to the authority of University Grant Commission (UGC) for UGC Scholarship. The authors gratefully acknowledge Scientists, all the fellows and students of Pharmaceutical Sciences and Research Division of Bangladesh Council of Scientific and Industrial Research (BCSIR) for providing laboratory facilities and for their co-operation.

\section{Authors' contributions}

MM has conducted all the experiments with the assistance of HS, NB and SRR. MM wrote the manuscript. FA and $\mathrm{NH}$ have supervised the entire project, experiments and manuscript preparation. AK, FA and $\mathrm{NH}$ revised the manuscript and worked to improve the quality of the final manuscript. All authors read and approved the final manuscript.

\section{Funding}

This work was supported by the University Grants Commission of Bangladesh. The grant numbers were 6(75)/UGC/Sci \& Tech /Bio-34/2017 and UGC/ Scholarship/1.157/ PhD/ 2015/Part-2/9835

Availability of data and materials Not applicable.

\section{Declarations}

Ethics approval and consent to participate

This study was approved by the Biological Research Division, Bangladesh Council of Scientific and Industrial Research (BCSIR), Dhaka, 1205, Bangladesh.

Consent for publication

Not applicable.

Competing interests

The authors declare that there are no conflicts of interest.

\section{Author details}

${ }^{1}$ Laboratory of Pharmaceutical Biotechnology and Bioinformatics,

Department of Genetic Engineering and Biotechnology, Faculty of Biological science and Technology, Jashore University of Science and Technology, 7408 Jashore, Bangladesh. ${ }^{2}$ Pharmaceutical Sciences and Research Division, Bangladesh Council of Scientific and Industrial Research, 1205 Dhaka, Bangladesh. ${ }^{3}$ Biological Research Division, BCSIR Laboratories, 1205 Dhaka, Dhaka, Bangladesh. ${ }^{4}$ Centre for Bioinformatics, Universität des Saarlandes, Saarbrücken, Germany. ${ }^{5}$ Laboratory of Pharmaceutical Biotechnology and Bioinformatics, Genetic Engineering and Biotechnology, Faculty of Biological science and Technology, Jashore University of Science and Technology, 7408 Jashore, Bangladesh.

Received: 19 April 2020 Accepted: 1 October 2021

Published online: 18 October 2021

References

1. Hoq ME, Islam MN, Kamal M, Wahab MA. Abundance and seasonal distribution of Penaeus monodon post larvae in the Sundarbans mangrove, Bangladesh. Hydrobiologia. 2001;457(1):97-104.

2. Karim MdA, Islam MdA, Islam MdM, Rahman MdS, Sultana S, Biswas S, Hosen MJ, Mozumder K, Rahman MM, Hasan MN. Evaluation of antioxidant, anti-hemolytic, cytotoxic effects and anti-bacterial activity of selected mangrove plants (Bruguiera gymnorrhiza and Heritiera littoralis) in Bangladesh. Clin Phytosci. 2020;6(1):1-12.

3. Mahmud I, Islam MK, Saha S, Barman AK, Rahman MM, Anisuzzman M, Rahman T, Al-Nahian A, Jahan R. Rahmatullah. Pharmacological and ethnomedicinal overview of Heritiera fomes: future prospects. Int Sch Res Not. 2014. https://doi.org/10.1155/2014/938543.

4. Aljaghthmi OH, Heba HM, Zeid IA. Antihyperglycemic properties of mangrove plants (Rhizophora mucronata and Avicennia marina): An overview. Adv Biol Res. 2017:11(4):161-70.

5. Simlai A, Roy A. Biological activities and chemical constituents of some mangrove species from Sundarban estuary: An overview. Pharmacogn Rev. 2021;7(14):170. https://dx.doi.org/10.4103 \%2F0973-7847.120518.

6. Choudhary MI, Khan S, Ahmad A. Communities of endophytic fungi in medicinal plant Withania somnifera. Pak J Bot. 2010;42(2):1281-7. 
7. Kaus S, Gupta S, Ahmed M, Dhar MK. Endophytic fungi from medicinal plants: A treasure hunts for bioactive compounds. Phytochem Rev. 2012; 11(4):487-505.

8. Jia M, Chen L, Xin H-L, Zheng C-J, Rahman K, Han T, Qin L-P. A friendly relationship between endophytic fungi and medicinal plants: A systematic review. Front Microbiol. 2016;7:906. https://doi.org/10.3389/fmicb.2016. 00906.

9. Simlai A, Roy A. Analysis of and correlation between phytochemical and antimicrobial constituents of Ceriops decandra, a medicinal mangrove plant, from Indian Sundarban estuary. J Med Plants Res. 2012;6(32):4755-65.

10. Mahmud I, Shahria N, Yeasmin S, labal A, Mukul EH, Gain S, Shilpi JA, Islam MK. Ethnomedicinal, phytochemical and pharmacological profile of a mangrove plant Ceriops Decandra Griff. D. in Hou. J Complement Integr Med. 2019;16(1). https://doi.org/10.1515/jcim-2017-0129.

11. Das K, Tiwari RKS, Shrivastava DK. Techniques for evaluation of medicinal plant products as antimicrobial agents: Current methods and future trends. J Med Plants Res. 2010;4(2):104-11.

12. Khan MIH, Sohrab MH, Rony SR, Tareq FS, Hasan CM, Mazid MA. Cytotoxic and antibacterial naphthoquinones from an endophytic fungus, Cladosporium sp. Toxicol Rep. 2016;3:861-5.

13. Chowdhury NS, Sohrab MH, Rony SR, Sharmin S, Begum MN, Rana MS, Hasan CM, et al. Identification and bioactive potential of endophytic fungi from Monochoria hastata (L.) Solms. Bangladesh J Bot. 2016;45(1):187-93.

14. $\quad \mathrm{Nn} \mathrm{D}, \mathrm{Jj}$ P. Bioactive metabolites from an endophytic fungus Penicillium $s p$. isolated from Centella asiatica. Curr Res Environ Appl Mycol. 2014;4(1):34-43.

15. Barnett $\mathrm{HL}$, Hunter BB. Illustrated genera of imperfect fungi. Minneapolis; Burgess Publishing Co.:1972. p. 241.

16. Cappuccino JG, Sherman N. Instructor guide for microbiology: A laboratory manual Tenth edition. Pearson: Rockland Community College; 2014.

17. Brand-Williams W, Cuvelier ME, Berset C. Use of a free radical method to evaluate antioxidant activity. LWT - Food Sci Technol. 1995;28(1):25-30.

18. Shah A, Rather MA, Hassan QP, Aga MA, Mushtaq S, Shah AM, Hussain A, Baba SA, Ahmed Z. Discovery of anti-microbial and anti-tubercular molecules from Fusarium solani: An endophyte of Glycyrrhiza glabra. J Appl Microbiol. 2017;122(5):1168-76.

19. Bauer AW, Kirby WM, Sherris JC, Turck M. Antibiotic susceptibility testing by a standardized single disc method. Am J Clin Pathol. 1966:45(4):493-6.

20. Gayathri S, Saravanan D, Radhakrishnan M, Balagurunathan R, Kathiresan K. Bioprospecting potential of fast-growing endophytic bacteria from leaves of mangrove and salt-marsh plant species. Indian J Biotech. 2010;9(4):397-402.

21. Alvindia DG, Hirooka Y. Identification of Clonostachys and Trichoderma spp. from banana fruit surfaces by cultural, morphological and molecular methods. Mycology. 2011;2(2):109-15.

22. Chowdhury NS, Sohrab MdH, Rana MdS, Hasan CM, Jamshidi S, Rahman KM. Cytotoxic Naphthoquinone and Azaanthraquinone derivatives from an endophytic Fusarium solani. J Nat Prod. 2017:80(4):1173-7.

23. Huang Z, Cai X, Shao C, She Z, Xia X, Chen Y, Yang J, Zhou S, Lin Y. Chemistry and weak antimicrobial activities of phomopsins produced by mangrove endophytic fungus Phomopsis sp. ZSU-H76. Phytochemistry. 2008; 69(7):1604-8.

24. Bharathidasan R, Panneerselvam A. Antioxidant activity of the endophytic fungi isolated from mangrove environment of Karankadu Ramanathakuram district. Int J Pharm Sci Res. 2012; doi:https://doi.org/10.13040/IJPSR.09758232.3(8).2866-69.

\section{Publisher's Note}

Springer Nature remains neutral with regard to jurisdictional claims in published maps and institutional affiliations.

\section{Submit your manuscript to a SpringerOpen ${ }^{\circ}$ journal and benefit from:}

- Convenient online submission

- Rigorous peer review

- Open access: articles freely available online

- High visibility within the field

- Retaining the copyright to your article

Submit your next manuscript at $\boldsymbol{\nabla}$ springeropen.com 